\title{
Financial Forecasting by Autoregressive Conditional Heteroscedasticity (ARCH) Family: A Case of Mexico
}

\author{
Vina Javed Khan', Abdul Qadeer², Bezon Kumar ${ }^{3,}$, \\ ${ }^{1}$ Department of Commerce, University of the Punjab, Gujranwala, Pakistan \\ ${ }^{2}$ Department of Finance, National University of Modern Languages, Lahore, Pakistan \\ ${ }^{3}$ Department of Economics, Varendra University, Rajshahi, Bangladesh \\ Email address: \\ vina.javed@gmail.com (V. J. Khan),dr.aqkhan@live.com (A. Qadeer), bezon.kumar3@gmail.com (B. Kumar) \\ ${ }^{*}$ Corresponding author
}

\section{To cite this article:}

Vina Javed Khan, Abdul Qadeer, Bezon Kumar. Financial Forecasting by Autoregressive Conditional Heteroscedasticity (ARCH) Family: A Case of Mexico. Journal of Public Policy and Administration. Vol. 2, No. 3, 2018, pp. 32-39. doi: 10.11648/j.jppa.20180203.13

Received: October 8, 2018; Accepted: October 29, 2018; Published: November 27, 2018

\begin{abstract}
Understanding and modeling the volatility measurements is important for forecasting the risk and for evaluating asset allocation decisions of stock market. The study have used the daily frequency data from January 1, 2002 to September 30 , 2016 as an in-sample period to perform empirical analyses for modeling and predicting the volatility dynamics of Mexican stock market (IPC). To facilitate the variance forecast, the competing models are ARCH (p, q), GARCH (p, q), and its variations i.e. Glosten Jagnnathon Runkle GARCH, GARCH in Mean, Exponential GARCH, and Quadratic GARCH. The results of residual diagnostics suggested that stock market of Mexico is characterized by heteroskedasticity, multicolinearity, non-normality, and serial correlation. Volatility measurements by ARCH and GARCH signify that the current conditional variance of Mexico is determined by its past price behavior and previous day volatility. Today's volatility does impact the current stock returns as indicated by GARCH-M. Results of EGARCH explained that any large size news produces high volatility as compared to small size news. Effects of bad news are greater on the volatility of the Mexican stock market than good news. GJR GARCH described the asymmetric behavior of returns and variance in the politically conflicted regime during 2006-2012. Moreover, QGARCH effect is not linear. Findings have the implications for individuals and corporate investors about retaining their risky stocks.
\end{abstract}

Keywords: Volatility, ARCH Family, Mexican Stock Market

\section{Introduction}

Financial forecasting is a broad subject with various subcategories and aspects. It may concern with estimating future profits and expenses of companies, impending financial and economic condition of countries, business valuation, risk accompanying the investment, and so forth. Predicting time series is one of the most challenging tasks due to its non-stationary and noisy characteristics [1-2]. Specifically concerned with stock markets, this study has investigated the volatility of Mexico Capital Market index. According to Figlewski, volatility is a departure from mean and this deviance entails risk [3]. Markowitz employed the volatility as a measure of risk in modern portfolio theory [4]. Forecasting volatility has plentiful implications for (a) options pricing like in option pricing model, (b) asset pricing like in Capital Asset Pricing Model (CAPM) introduced by Sharpe, Lintner and Mossin (c) risk management such as Value at Risk (VaR) models and hedging, (d) portfolio management, and (e) macroeconomic stability [5-7].

Many models have been developed so far to account for the stylized facts of heavy tails and sharply peaked distribution (leptokurtosis), leverage effect ${ }^{1}$, and volatility clustering $^{2}$ in stock market returns. These include ARCH models, Autoregressive Moving Average (ARMA) models, Stochastic Volatility (SV) models, threshold models, and

\footnotetext{
1 Leverage effect explains the negative correlation between asset's present returns and its future volatility [8]

2 Volatility clustering means that large changes lead towards large changes (negative/positive) and similar is for small changes [9]
} 
regime switching models. ARCH family models are used for modeling and forecasting conditional volatility of asset returns. Engle developed ARCH and its extensions consist of Generalized ARCH (GARCH) which was proposed by Bollerslev and Taylor [10-12]. Variations of GARCH include GARCH in Mean (GARCH-M), Exponential GARCH (EGARCH), and Integrated GARCH (IGARCH) developed by Nelson, Glosten Jagnnathon Runkle GARCH (GJRGARCH) by Glosten at al., Quadratic GARCH (QGARCH) by Engle and $\mathrm{Ng}$, and Asymmetric GARCH (AGARCH) by Engle [13-16]. Past studies have shown consensus that no model is superior however these are alternative specifications and extensions of one model that are aimed to capture the characteristics of financial time series.

Stock markets' volatility forecasting has been done on various developed and developing countries by utilizing many econometric models. For example, Brooks and Burke used the stock market data of the United States and found the GARCH family models perform better [17]. Brailsford and Faff forecasted the volatility of the Australian stock market index using GARCH models [18]. For modeling the stock market volatility, Mcmillan et al. worked upon the United Kingdom stock market; Franses and Ghijsels analyzed the capital markets of Netherlands, Spain, Germany, and Italy; Wei studied the Chinese equity market; Pandey analyzed the Indian stock market; and Miron and Tudor worked upon daily stock returns of US and Rumania [19-23].

None of the studies, as per researchers' knowledge are targeted on the emerging market of Mexico for scrutinizing conditional volatility using ARCH, GARCH, GARCH-M, EGARCH, QGARCH, and GJR-GARCH models. So, this research would fill this gap by answering the following research questions.

(1) Is the current volatility of Mexbol estimated by squared residuals and volatility of previous periods?

(2) Is there any relationship (positive/negative) between Mexbol stock returns and current volatility?

(3) What is the impact of size (large/small) and sign $(\mathrm{good} / \mathrm{bad})$ of news on current volatility?

(4) Does the bad news impact higher on the conditional volatility or the good news?

The paper is organized in different sections. After reviewing the relevant literature, data and methodology is given in section 2. Section 3 presents the results and discussion. Section four concludes the study.

Numerous empirical studies have been conducted on the forecasting of conditional volatility using $\mathrm{ARCH}$ family models contextualizing the developing and developed countries. Claessen and Mittnik employed GARCH models on the German (DAX) options market and found that historical returns do not provide useful information to predict the current volatility [24]. Another study predicted the Japanese stock market volatility concerning some macroeconomic variables using GARCH models and discovered no influence of these on volatility. Su applied GARCH and EGARCH models on the Chinese stock market and concluded that its volatility is more sensitive to crisis period and bad news [25].

ARCH family models have been applied to encapsulate different characteristics of stock markets' conditional returns and variances. Using non-linear GARCH models, Iranian capital market assessed to have the same impact of good and bad news of equal size and the absence of asymmetric volatility [26]. By employing ARCH and GARCH models, Midhra found time-varying volatility of Indian stock market to be more sensitive to bad news from 1991 to 2009. Through applying GARCH models on the Saudi capital market, Abdalla and Suliman discovered the persistence of previous period volatility and presence of risk premium with the positive sign [27-28]. Ahmed and Suliman applied some univariate GARCH models on the Khartoum Stock Exchange (KSE) of Sudan and revealed that there is the high persistence of prior period volatility and leverage effect exists [29]. Chowdhury and Ratan performed volatility forecasting on Dhaka Stock Exchange of Bangladesh using GARCH and GJR-GARCH models and concluded equity returns are not always a function of its variance and conditional volatility exhibits symmetric behavior [30]. Arshad et al. identified the Karachi Stock Exchange of Pakistan as highly volatile [31]. Its current volatility depends upon previous periods residuals and absence of leverage effect indicates that greater volatility is caused by positive returns. Wong and Kok studied equity markets' conditional volatility of Malaysia, Thailand, Singapore, Philippines, and Indonesia using ARCH-M, TARCH, and EGARCH and identified the insignificant asymmetric behavior of their stock returns [32].

Some studies are aimed at comparison of different ARCH family models or among several forecasting models. Kuen and Hoong declared Exponentially Weighted Moving Average (EWMA) method as superior to the GARCH model and naive method based on the historical variance in forecasting volatility of Singapore stock market [33]. AbdElaal worked upon EWMA, ARCH, GARCH, GJRGARCH, and GARCH models for Egyptian stock market and found EGARCH to be the best model among these [34]. Alberg et al. analyzed the conditional variance of Tel Aviv Stock Exchange (TASE) indices of Israel using GARCH, EGARCH, GJR-GARCH, and Asymmetric PARCH (APARCH) models and realized the EGARCH to be more useful than others in inculcating dynamic behavior of stock returns [35]. Further, comparison was made between Heterogenous Auto Regressive (HAR) and GARCH class modeling for their performance to capture the asymmetric volatility in 19 equity indices form Asia, America, Australia, and Europe. The results indicated significant accuracy of GARCH models during high volatility (asymmetric volatility in equity markets around the world). Opposing, Vortelinos regarded HAR model better than nonlinear models like GARCH, neural networks, and Principal Components Combining for realized volatility forecasting [36].

None of the studies, as per researchers' knowledge have targeted forecasting the conditional volatility of Mexico despite its important place in North American Free Trade 
Area (NAFTA) and well as in Next Eleven (N-11) emerging economies [37-38].

\section{Data and Methods}

Mexican Stock Exchange is the only stock exchange of Mexico, usually referred to as Mexican Bolsa (Mexbol). It is ranked the second largest by market capitalization in Latin America. Índice de Precios y Cotizaciones (IPC) is the benchmark index. For modeling and forecasting the volatility of the Mexican Stock Exchange Index, this paper used daily closing prices for the sample period January 1, 2002 to September 30, 2016. The dataset was obtained from Yahoo Finance and comprised 5832 observations. Continuously compounded returns $\mathrm{R}_{\mathrm{t}}$ for daily stock prices of Mexbol Index were calculated using the formula $\mathrm{Rt}=\ln (\mathrm{Pt} / \mathrm{Pt}-1)$ where $\mathrm{P}_{t}$ and $\mathrm{P}_{\mathrm{t}-1}$ represent the closing stock prices of Mexbol Index for two successive days.

Before application of univariate $\mathrm{ARCH}$ and $\mathrm{GARCH}$ models, authors firstly examine the residuals for autocorrelation and heteroscedasticity issues. To check for these econometric problems, residuals $e_{t}$ were obtained by estimating the conditional mean equation through ordinary least square (OLS) method. For estimating residuals, conditional mean equation using autoregressive (AR) process is:

$$
\mathrm{R}_{\mathrm{t}}=\alpha+\beta \mathrm{R}_{\mathrm{t}-1}+\mathrm{e}_{\mathrm{t}}
$$

After finding the residuals, existence of serial correlation was checked through Breusch-Godfrey Serial Correlation Lagrange Multiplier (LM) Test. The decision was based on the $\mathrm{p}$-value of chi-square for the null hypothesis of no serial correlation. Heteroscedasticity problem was tested against the null hypothesis that there is no $\mathrm{ARCH}$ effect or there exists heteroscedasticity. $\mathrm{P}$ value less than 0.05 provides a base for acceptance or rejection of the null hypothesis.

\section{Volatility Models}

Volatility is not exactly similar to risk, however, both terms are related. Commonly, risk is linked with some unfavorable outcome while volatility is specifically for uncertainty which might occur due to any positive event [39]. This study have used variance to measure the volatility of Mexican stock returns.

\subsection{Autoregressive Conditional Heteroscedasticity (ARCH) Model}

The ARCH model was first introduced by Engle being the first model to accommodate heteroscedasticity problem for volatility measurement of stock returns [10]. The ARCH model evaluates the variance of returns as a function of previous period innovations or disturbances. Conditional mean and variance equation of $\mathrm{q}$ order Autoregressive Conditional Heteroscedasticity i.e. ARCH (q) is specified as:

$$
\begin{aligned}
& \text { Mean equation } R_{t}=\omega+\sum_{i=1}^{\mathrm{q}} \theta_{\mathrm{i}} \mathrm{R}_{\mathrm{t}-\mathrm{i}}+\varepsilon_{\mathrm{t}} \\
& \text { Variance equation } \sigma_{\mathrm{t}}^{2}=\alpha+\sum_{\mathrm{i}=1}^{\mathrm{q}} \gamma_{\mathrm{i}} \varepsilon_{\mathrm{t}-\mathrm{i}}^{2}
\end{aligned}
$$

$R_{t}$ is the current period return of an asset. This study is related to stock returns so $R_{t}$ will be stock returns of Mexbol Index and these are predicted by its own lags and residual term $\varepsilon_{\mathrm{t}} \cdot \sigma_{\mathrm{t}}^{2}$ denotes the volatility of stock returns at the time $\mathrm{t}$ i.e. current period and measured by sigma square. Current period volatility is predicted by squared errors of prior periods i.e. $\varepsilon_{\mathrm{t}-\mathrm{i}}^{2}$. $\alpha$ is the constant term and $\gamma$ is the coefficient of $\varepsilon_{\mathrm{t}-\mathrm{i}}^{2}$. $\omega$ and $\theta$ are parameters.

\subsection{Generalized Autoregressive Conditional Heteroscedasticity (GARCH) Model}

Bollersley propounded the Generalized Autoregressive Conditional Heteroscedasticity (GARCH) model which suggested that current volatility of an asset return is not only determined by squared errors of previous periods but also by its own lags [11]. Conditional mean and variance equation for $\operatorname{GARCH}(p, q)$ model is formed as:

$$
\begin{aligned}
& \text { Mean equation } \mathrm{R}_{\mathrm{t}}=\omega+\sum_{\mathrm{i}=1}^{\mathrm{q}} \theta_{\mathrm{i}} \mathrm{R}_{\mathrm{t}-\mathrm{i}}+\varepsilon_{\mathrm{t}} \\
& \text { Variance equation } \sigma_{\mathrm{t}}^{2}=\alpha+\sum_{\mathrm{i}=1}^{\mathrm{p}} \beta_{\mathrm{i}} \sigma_{\mathrm{t}-\mathrm{i}}^{2}+\sum_{\mathrm{j}=1}^{\mathrm{q}} \gamma_{\mathrm{j}} \varepsilon_{\mathrm{t}-\mathrm{j}}^{2}
\end{aligned}
$$

Here, $p$ represents the order of lagged volatility $(\mathrm{GARCH}$ term) and $q$ is the lagged order of squared error $(\mathrm{ARCH}$ term). $\sigma_{\mathrm{t}-\mathrm{i}}^{2}$ denotes the lagged values of volatility. $\alpha, \beta$ and $\gamma$ are parameters.

\subsection{GARCH in Mean (GARCH-M) Model}

In the finance world, the stock returns may be determined by its own volatility. Engel et al. developed GARCH in Mean model to account for this aspect. GARCH-M is an extension of ARCH family models which permits the condition to mean the return to being estimated by its standard deviation or variance [40]. GARCH-M (p, q) can be written as:

$$
\begin{aligned}
& \text { Mean equationR } R_{t}=\omega+\sum_{i=1}^{q} \theta_{i} R_{t-i}+\varphi \sigma_{t}+\varepsilon_{t} \\
& \text { Variance equation } \sigma_{t}^{2}=\alpha+\sum_{i=1}^{p} \beta_{i} \sigma_{t-i}^{2}+\sum_{j=1}^{q} \gamma_{j} \varepsilon_{t-j}^{2}
\end{aligned}
$$

In the conditional mean equation, the coefficient of $\sigma_{t}$ is called risk premium parameter $\varphi$. The positive sign of $\varphi$ shows that the asset return has a positive relation with its volatility and vice versa. It signifies that if risk (standard deviation, $\sigma_{t}$ ) of the security increases, returns will grow. $\beta$ and $\gamma$ are coefficients of GARCH and ARCH term respectively.

ARCH, GARCH, and GARCH-M models, discussed above, do not account for the leverage effects in stock returns. Leverage effect is described as the negative relationship between the stock returns and future volatility [41]. In these models, the conditional variance was dependent upon the past conditional volatility and lag values of squared errors. Increase or decrease in the $\varepsilon_{\mathrm{t}}$ did not influence the conditional variance. In other words, the variance of the returns was only affected by the size, but not by the sign of returns. Hence, to inculcate this aspect, asymmetric GARCH models like EGARCH, TARCH, and QGARCH were developed by researchers. 


\subsection{Exponential GARCH (EGARCH) Model}

In 1991, Nelson developed the EGARCH model that encapsulate leverage effect and the asymmetric responses of conditional variance as a result of shocks [13]. Mean equation is similar to equation (4) and following are the specifications of conditional mean and variance for $\operatorname{EGARCH}(p, q)$ model.

$$
\text { Mean equation } \mathrm{R}_{\mathrm{t}}=\omega+\sum_{\mathrm{i}=1}^{\mathrm{q}} \theta_{\mathrm{i}} \mathrm{R}_{\mathrm{t}-\mathrm{i}}+\varepsilon_{\mathrm{t}}
$$

$$
\text { Variance equation } \operatorname{Ln} \sigma_{\mathrm{t}}^{2}=\alpha+\sum_{\mathrm{j}=1}^{\mathrm{p}} \gamma_{\mathrm{j}}\left|\frac{\varepsilon_{\mathrm{t}-\mathrm{j}}}{\sigma_{\mathrm{t}-\mathrm{j}}^{2}}\right|+\sum_{\mathrm{j}=1}^{\mathrm{p}} \rho_{\mathrm{j}} \frac{\varepsilon_{\mathrm{t}-\mathrm{j}}}{\sigma_{\mathrm{t}-\mathrm{j}}^{2}}+
$$

$$
\sum_{\mathrm{i}=1}^{\mathrm{q}} \beta_{\mathrm{i}} \operatorname{Ln}\left(\sigma_{\mathrm{t}-\mathrm{i}}^{2}\right)
$$

In this model, $\rho$ signifies the asymmetric impact of shocks on conditional volatility. The second term signifies the magnitude impact which shows that large size news causes high volatility and small size news leads to low volatility. The third term of equation (9) indicates the sign effect. This means that zero value of $\rho$ will reveal the absence of leverage impact and its positive or negative value ensure the presence of asymmetric behavior of stock returns [29]. The last term denotes the persistence of previous periods of volatility.

\subsection{Glosten Jagnnathon Runkle GARCH (GJR-GARCH) Model}

GJR-GARCH that is also known as Threshold GARCH (TGARCH) is another model for volatility measurement that can handle the leverage effect. Volatility forecasting using TGARCH process permits to analyze the impacts of good or bad news on the conditional volatility by introducing a dummy variable. Conditional mean and variance for TGARCH (p, q) process can be generally specified as:

$$
\text { Mean equation } R_{t}=\omega+\sum_{i=1}^{q} \theta_{i} R_{t-i}+\varepsilon_{t}
$$

Variance equation $\sigma_{\mathrm{t}}^{2}=\alpha+\sum_{\mathrm{i}=1}^{\mathrm{p}} \beta_{\mathrm{i}} \sigma_{\mathrm{t}-\mathrm{i}}^{2}+\sum_{\mathrm{j}=1}^{\mathrm{q}} \gamma_{\mathrm{j}} \varepsilon_{\mathrm{t}-\mathrm{j}}^{2}+$

$$
\sum_{\mathrm{j}=1}^{\mathrm{q}} \rho_{\mathrm{j}}\left(\mathrm{D} * \varepsilon_{\mathrm{t}-\mathrm{j}}^{2}\right)
$$

D represents the dummy variable in equation (11) and its value is 1 for the time period December 1, 2006 to November 30, 2012. This period represents the presidential tenure of Felipe Calderón of Mexico which is characterized by a large increase in organized crime, illegal drug trade, lawlessness, and political corruption. Use of army by president Calderón to resolve these issues worsened the situation [42]. For the rest of the sample, the value of the dummy variable was zero. $\rho$ measures the leverage effect and if its value was found to be significant and positive then bad news or negative shocks impact higher on the conditional volatility.

\subsection{Quadratic GARCH (QGARCH) Model}

Engle and $\mathrm{Ng}$ developed another model that can account for the asymmetric impact of shocks [15]. This model adds error term as a regressor in the variance equation. QGARCH $(p, q)$ then can be written as:

$$
\begin{aligned}
\text { Mean equation } \mathrm{R}_{\mathrm{t}}= & \omega+\sum_{\mathrm{i}=1}^{\mathrm{q}} \theta_{\mathrm{i}} \mathrm{R}_{\mathrm{t}-\mathrm{i}}+\varepsilon_{\mathrm{t}} \\
\text { Variance equation } \sigma_{\mathrm{t}}^{2}= & \alpha+\sum_{\mathrm{i}=1}^{\mathrm{p}} \beta_{\mathrm{i}} \sigma_{\mathrm{t}-\mathrm{i}}^{2}+\sum_{\mathrm{j}=1}^{\mathrm{q}} \gamma_{\mathrm{j}} \varepsilon_{\mathrm{t}-\mathrm{j}}^{2}+ \\
& \sum_{\mathrm{j}=1}^{\mathrm{q}} \rho_{\mathrm{j}} \varepsilon_{\mathrm{t}-\mathrm{j}}
\end{aligned}
$$

GARCH effect would be quadratic, and non-linear if $\rho_{\mathrm{j}}$ value was found to be significant.

\section{Results and Discussion}

Figure 1 displays the result of descriptive statistics and normality test for Mexbol index returns. The daily average return for the chosen time series was close to zero. A normal distribution has 0 skewness and a kurtosis of 3. In this study, skewness coefficient of 0.07 is positive and not equal to zero which suggests that the distribution is positively skewed to right. Kurtosis of 11.89 indicates the empirical distributions is leptokurtic, being greater than 3. It also reveals the presence of extreme values and hence, fait tails. P-value against the Jarque-Bera test of normality rejects the null hypothesis of normality as its value is significant at $5 \%$ level of significance.

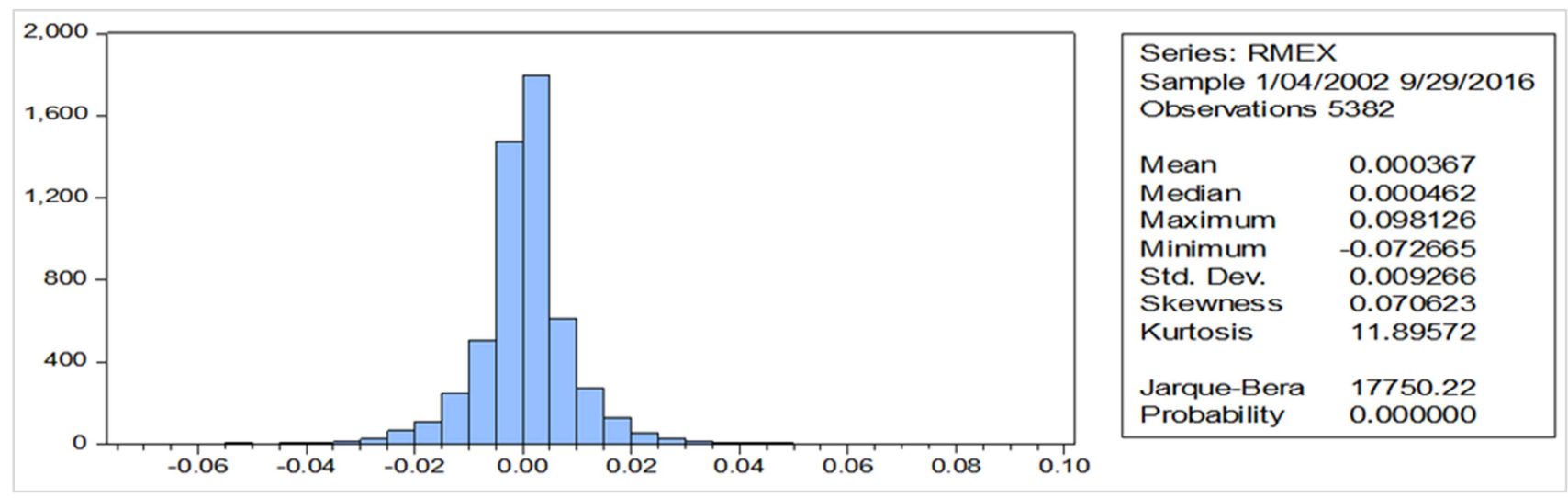

Figure 1. Summary statistics and normality test of Mexico's return time series for the period 1st January 2002 to 30 th September 2016. 


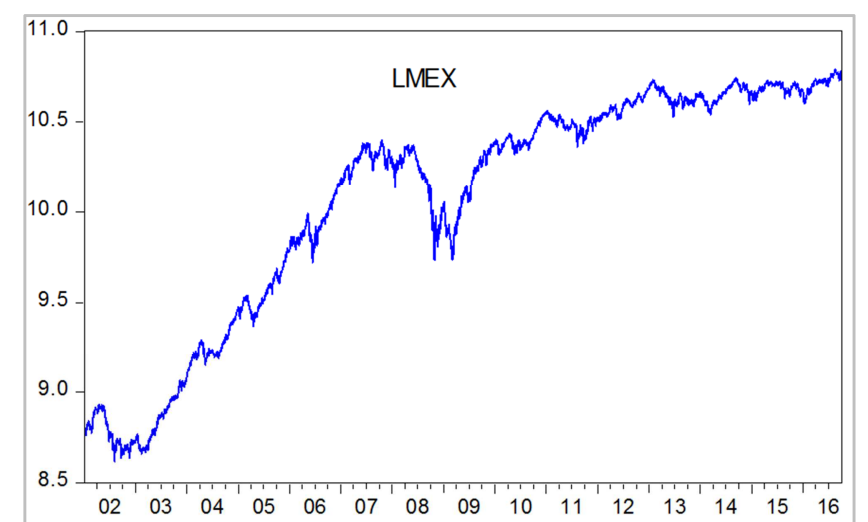

Figure 2. Daily closing log prices of Mexican Stock Exchange Index (Mexbol) from 1st January 2002 to 30th September 2016.

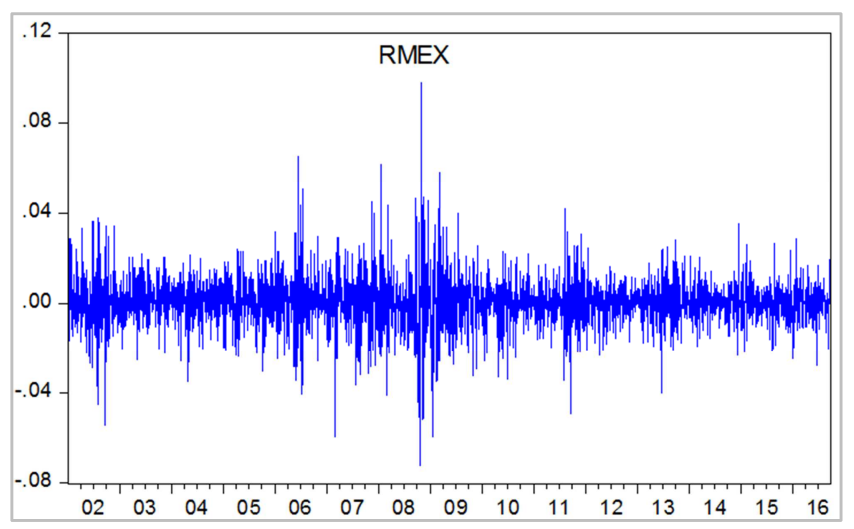

Figure 3. Daily Stock Returns of Mexican Stock Exchange Index (Mexbol) from 1st January 2002 to 30th September 2016.
Daily closing log prices of Mexbol exhibit an upward trend as evident from Figure 2. The major downward trend in its prices was observed in late 2007 to 2009 which might be due to financial crisis of 2007 occurred in United States (US). Daily returns of Mexican Bolsa (Mexbol) also show the greater volatility during this crisis as displayed in figure 3 .

Table 1. Unit Root Analysis.

\begin{tabular}{lll}
\hline \multirow{2}{*}{ Variables/series } & \multicolumn{2}{l}{ Augmented Dickey Fuller } \\
\cline { 2 - 3 } & Levels & 1st Difference \\
\hline Mexico & -62.51 & -27.99 \\
Critical Values & & \\
1\% Level & -3.96 & -3.96 \\
5\% Level & -3.41 & -3.41 \\
10\% Level & -3.13 & -3.13 \\
\hline
\end{tabular}

Stationarity of sample return series was tested by employing Augmented Dickey Fuller test as displayed in Table 1. Test results revealed the stationarity of Mexbol stock returns series at levels and at first difference. Decision was based on the comparison between the absolute values of $t$ statistic and corresponding critical values at $5 \%$ significance level. Greater absolute t-statistic value suggested the stationarity of Mexbol daily stock return series.

Pre-requisites of applying ARCH family models for financial forecasting are presence of heteroscedasticity and autocorrelation in the residuals. For this purpose, equation (1) is estimated through autoregressive process (1) using least square method and residual diagnostics are applied. Results for diagnostic tests are given in table 2 .

Table 2. Diagnostic Tests on Standardized Residuals.

\begin{tabular}{lll}
\hline & Heteroscedasticity Test -ARCH & Breusch-Godfrey Serial Correlation LM Test \\
\hline F-statistic & 169.18 & 3.17 \\
Prob. F(1,5378) & 0.00 & 0.04 \\
Obs*R-squared & 164.09 & 6.33 \\
Prob. Chi-Square(1) & 0.00 & 0.04 \\
\hline
\end{tabular}

Heteroscedasticity of the residuals is present as Prob. Chi-Square is less than 0.05 (see table 2). So, null of no ARCH effect is rejected. Breusch-Godfrey serial correlation LM test identified the autocorrelation problem in residuals (see table 2) as its Prob. Chi-Square value of less than 0.05 rejected the null of no serial correlation.

Results of financial time series was detected to have the characteristics of heteroscedasticity and autocorrelation in residuals. So, ARCH family models can be applied for forecasting the conditional volatility of Mexbol's returns.

Conditional volatility is estimated using one lag. According to Brooks and Bruke lag order one is enough to encapsulate the impact of volatility clustering [17]. By using simple ARCH family models, Table 3 shows the conditional mean and conditional variance equations of $\mathrm{ARCH}, \mathrm{GARCH}$, and GARCH-M.

Table 3. Estimation of Conditional Volatility Using ARCH $(1), \operatorname{GARCH}(1,1)$, and $\operatorname{GARCH-M}(1,1)$ Process.

\begin{tabular}{|c|c|c|c|c|c|c|}
\hline & \multicolumn{3}{|c|}{ Mean equation } & \multicolumn{3}{|c|}{ Variance equation } \\
\hline & $\omega$ & $\boldsymbol{\theta}$ & $\varphi$ & $\alpha$ & $\gamma$ & $\beta$ \\
\hline $\mathrm{ARCH}(1)$ & $0.00(0.00)$ & $0.09(0.00)$ & & $0.00(0.00)$ & $0.39(0.00)$ & \\
\hline $\operatorname{GARCH}(1,1)$ & $0.00(0.00)$ & $0.12(0.00)$ & & $0.00(0.00)$ & $0.04(0.00)$ & $0.94(0.00)$ \\
\hline GARCH-M $(1,1)$ & $-0.001(0.09)$ & $0.12(0.00)$ & $0.15(0.00)$ & $0.00(0.00)$ & $0.04(0.00)$ & $0.95(0.00)$ \\
\hline
\end{tabular}

Note: Figures in the brackets indicate p-values.

In $\mathrm{ARCH}$ (1) process, the significant $\mathrm{p}$-value of $\theta$ suggests that today's return of Mexico stock market index is predicted by the past return. Its positive coefficient of 0.09 shows that current return will be $9 \%$ more than the previous day return. In variance equation of $\mathrm{ARCH}$ (1) process, significant $\mathrm{p}$ value (i.e. less than 0.05 ) of $\mathrm{ARCH}$ term $\beta$ indicates that 
previous day innovations explain the current volatility. Positive coefficient of lagged squared residuals $\beta$ exhibit today's volatility will be greater.

Estimation of GARCH $(1,1)$ model also accounts for the previous period volatility in the analysis of today's volatility. It captures the persistence of last period volatility. Variance equation of GARCH $(1,1)$ process (see table 3 ) depicts that today's conditional volatility is significantly dependent upon prior day innovations $\beta$ as well as previous period volatility $\gamma$ that is GARCH term. The positive value of $\gamma$ revealed that $95 \%$ volatility of last day transfers to the next day.

GARCH in Mean $(1,1)$ model consider that today's stock return might be affected by today's volatility. As p-value of GARCH-M that is $\varphi$ is significant which suggests that today's return of Mexico stock market is predicted by today's volatility and $1 \%$ increase in current volatility cause $14 \%$ increase in today's stock return. The coefficient of GARCH$\mathrm{M}$ term is the risk premium parameter of equation (6). Variance equation signifies that previous period's squared residuals and variance positively and significantly determines the today conditional volatility.

As discussed previously, EGARCH model incorporates the asymmetric responses of variance to the shocks. Conditional volatility in this model is determined by the size as well as by sign of news (positive or negative). For EGARCH $(1,1)$ process, errors were estimated using equation (8). Intercept term [ $\alpha$ of equation (9)] is negative and significant. It suggests that there are many other variables or factors that might affect the today's stock market volatility and should be part of the equation. The coefficient of size effect $\sum_{\mathrm{j}=1}^{\mathrm{q}} \gamma_{\mathrm{j}}\left|\frac{\varepsilon_{\mathrm{t}-\mathrm{j}}}{\sigma_{\mathrm{t}-\mathrm{j}}^{2}}\right|$ and has the positive sign; its $\mathrm{p}$-value is significant which suggest that large size news leads to high volatility and small size cause little volatility. $\rho$ of equation (9) which represents the sign effect $\sum_{j=1}^{p} \rho_{j} \frac{\varepsilon_{t-j}}{\sigma_{t-j}^{2}}$. The P-value of $\rho$ is negatively significant which means that the leverage effect exists and bad news impact higher on the volatility of stock returns as compared to the good news. These results entail that the impact of market crashes have higher on the volatility than the market bubble because of greater perceived uncertainty [9]. The significant value of coefficient $\beta$ indicates that previous day volatility persists and contribute $98.42 \%$ to next day conditional volatility.

Table 4. Estimation of Conditional Volatility Using $\operatorname{EGARCH}(1,1)$, GJR-GARCH(1,1), and QGARCH(1,1) Process.

\begin{tabular}{|c|c|c|c|c|c|c|}
\hline & \multicolumn{2}{|c|}{ Mean equation } & \multicolumn{4}{|c|}{ Variance equation } \\
\hline & $\omega$ & $\theta$ & $\alpha$ & $\beta$ & $\gamma$ & $\rho$ \\
\hline EGARCH $(1,1)$ & $0.00(0.04)$ & $0.11(0.00)$ & $-0.22(0.00)$ & $0.98(0.00)$ & $0.09(0.00)$ & $-0.08(0.00)$ \\
\hline GJR-GARCH $(1,1)$ & $0.00(0.00)$ & $0.12(0.00)$ & $0.00(0.00)$ & $0.94(0.00)$ & $0.01(0.00)$ & $-0.001(0.00)$ \\
\hline QGARCH $(1,1)$ & $0.00(0.99)$ & $0.16(0.00)$ & $0.00(0.00)$ & $0.94(0.00)$ & $-0.65(0.00)$ & $0.69(0.00)$ \\
\hline
\end{tabular}

Note: Figures in the brackets indicates p-values.

Next asymmetric model of $\mathrm{ARCH}$ family in table 4 is Threshold GARCH model. It also takes into account the leverage effect on the conditional volatility by introducing a dummy variable into the TGARCH $(1,1)$ model. The dummy variable is a politically corrupt period of Mexico $1^{\text {st }}$ December 2006 to $30^{\text {th }}$ November 2012 as discussed before.

TGARCH $(1,1)$ model also measure the leverage effect. In table 4 , coefficient $\rho$ of dummy variable that measure the impact of good news and bad news. As p-value of the dummy is significant that is less than 0.05 which signifies the asymmetric behavior of stock returns along with the different influence of good and bad news on the Mexbol stock market. Coefficient $\rho$ of dummy variable in variance equation (see table 4) is negative which indicates that good news has greater sensitivity than the bad news to the conditional volatility. It is evident from the minor value of coefficient of dummy.

Results of QGGARCH indicates that conditional volatility of Mexbol's stock returns is not lagged squared residuals and lagged volatility but also by previous day's residuals. Significant $\mathrm{p}$-value of $\varepsilon_{\mathrm{t}-\mathrm{j}}$ suggests that GARCH effect on conditional volatility exist and it is not linear but quadratic.

\section{Conclusion}

Financial forecasting of stock market's volatility has several knocks on effects. Variation in the stock market volatility influence the consumer spending through the wealth effect, investors' readiness for retaining the risky assets and securities, and also the companies' decisions about investment. Forecasting of conditional volatility is thus important for risk management, portfolio allocation, and asset pricing decisions. This study on Mexico stock market would definitely contribute academically to the present literature related to modeling and forecasting of conditional volatility using $\mathrm{ARCH}$ and $\mathrm{GARCH}$ family models within the context of emerging countries. Results of $\operatorname{GARCH}(1,1)$ have indicated that the conditional volatility of Mexbol's returns depends upon the previous day disturbances and volatility. GARCH-M determined that current return is forecasted by current volatility along with its lagged returns. The large size and negative news were discovered to be highly associated with greater volatility as indicated by $\operatorname{EGARCH}(1,1)$ process. Conditional volatility was uncovered to have asymmetric behavior and observed greater sensitivity to good news. In future, this research can be extended by comparing the performance of these ARCH family models in capturing the stock market volatility of Mexico. These ARCH models can be applied to other unexplored emerging markets for the same purpose. 


\section{References}

[1] Abu-Mostafa, Y. S., and Atiya, A. F. (1996). Introduction to financial forecasting. Applied Intelligence 6 (3), 205-213.

[2] Sánchez A, V. D. (2002). Frontiers of research in BSS/ICA. Neurocomputing 49 (1-4), 7-23.

[3] Figlewski, S. (1997). Forecasting volatility. Financial markets, institutions and instruments $6(1), 1-88$.

[4] Markowitz, H. (1952). Portfolio selection. The journal of finance 7 (1), 77-91.

[5] Sharpe, W. F. (1964). Capital asset prices: A theory of market equilibrium under conditions of risk. The journal of finance 19 (3), 425-442.

[6] Lintner, J. (1965). The valuation of risk assets and the selection of risky investments in stock portfolios and capital budgets. The Review of Economics and Statistics47 (1), 1337.

[7] Mossin, J. (1966). Equilibrium in a capital asset market. Econometrica 34 (4), 768-783.

[8] Black, F. (1976). Studies of stock price volatility changes. Proceedings of the 1976 Meeting of the Business and Economic Statistics Section, American Statistical Association 171-181.

[9] Mandelbrot, B. (1963). The variation of certain speculative prices. The Journal of Business 36 (4), 394-419.

[10] Engle, R. F. (1982). Autoregressive conditional heteroscedasticity with estimates of the variance of United Kingdom inflation. Econometrica 50 (4), 987-1007.

[11] Bollerslev, T. (1986). Generalized autoregressive conditional heteroscedasticity. Journal of Econometrics 3 1(3), 307-327.

[12] Taylor, S. J. (1986). Modeling financial time series. Chichester, UK: John Wiley and Sons.

[13] Nelson, D. B. (1991). Conditional heteroscedasticity in asset returns: A new approach. Econometrica59 (2), 347-370.

[14] Glosten, L. R., Jagannathan, R., and Runkle, D. E. (1993). On the relation between the expected value and the volatility of the nominal excess return on stocks. The journal of finance 48 (5), 1779-1801.

[15] Engle, R. F., and Ng, V. K. (1993). Measuring and testing the impact of news on volatility. The journal of finance 48 (5), 1749-1778.

[16] Engle, R. F. (1990). Stock volatility and the crash of 87: Discussion. The Review of Financial Studies 3 (1), 103-106.

[17] Brooks, C., and Burke, S. P. (1998). Forecasting exchange rate volatility using conditional variance models selected by information criteria. Economics Letters 61 (3), 273-278.

[18] Brailsford, T. J., and Faff, R. W. (1996). An evaluation of volatility forecasting techniques. Journal of Banking and Finance 20 (3), 419-438.

[19] McMillan, D., Speight, A., and Apgwilym, O. (2000). Forecasting UK stock market volatility. Applied Financial Economics 10 (4), 435-448.
[20] Franses, P. H., and Ghijsels, H. (1999). Additive outliers, GARCH and forecasting volatility. International Journal of Forecasting 15 (1), 1-9.

[21] Wei, W. (2002). Forecasting stock market volatility with nonlinear GARCH models: a case for China. Applied Economics Letters 9 (3), 163-166.

[22] Pandey, A. (2002). Extreme-value volatility estimators and their empirical performance in Indian capital markets. NSE Working Paper No. 52.

[23] Miron, D., and Tudor, C. (2010). Asymmetric conditional volatility models: Empirical estimation and comparison of forecasting accuracy. Romanian Journal of Economic Forecasting 9 (3), 74-92.

[24] Claessen, H., and Mittnik, S. (2002). Forecasting stock market volatility and the informational efficiency of the DAX-index options market. The European Journal of Finance 8 (3), 302321.

[25] Su, C. (2010). Application of EGARCH model to estimate financial volatility of daily returns: The empirical case of China (Unpublished master's thesis). University of Gothenburg, Swedan.

[26] Oskooe, S. A. P., and Shamsavari, A. (2011). Asymmetric effects in emerging stock markets-The case of Iran stock market. International Journal of Economics and Finance 3 (6), 16-24.

[27] Mishra, P. K. (2010). A GARCH model approach to capital market volatility: The case of India. Indian Journal of Economics and Business9 (3), 631-641.

[28] Abdalla, S. Z. S., and Suliman, Z. (2012). Modelling stock returns volatility: Empirical evidence from Saudi stock exchange. International Research Journal of Finance and Economics 85, 166-179.

[29] Ahmed, A. E. M., and Suliman, S. Z. (2011). Modeling stock market volatility using GARCH models evidence from Sudan. International Journal of Business and Social Science 2 (23).

[30] Chowdhury, A., and Ratan, S. (2012). Estimating Dhaka stock market volatility: A comparison between standard and asymmetric GARCH models. ABAC Journal 32 (2), 63-70.

[31] Arshad, I., Rani, H., and Shaikh, A. W. (2012). Volatility modeling of Karachi stock exchange. Sindh University Research Journal-SURJ (Science Series) 44 (1), 125-130.

[32] Wong, Y. C., and Kok, K. L. (2005). A comparison forecasting models for ASEAN equity markets. Sunway Academic Journal 2, 1-12.

[33] Kuen, T. Y., and Hoong, T. S. (1992). Forecasting volatility in the Singapore stock market. Asia Pacific Journal of Management 9 (1), 1-13.

[34] AbdElaal, M. A. (2011). Modeling and forecasting time varying stock return volatility in the Egyptian stock market. International Research Journal of Finance and Economics78 (2011), 96-113.

[35] Alberg, D., Shalit, H., and Yosef, R. (2008). Estimating stock market volatility using asymmetric GARCH models. Applied Financial Economics 18 (15), 1201-1208. 
[36] Vortilinos, D. (2017). Forecasting realized volatility: HAR against Principal Components Combining, neural networks and GARCH. Research in international business and finance 39, 824-839.

[37] Hufbauer, G. C., and Schott, J. J. (1993). NAFTA: An assessment. Washington, D. C.: Institute for International Economics.

[38] O'neill, J. (2011). The Growth Map: Economic opportunity in the BRICs and beyond. New York: Penguin.

[39] Poon, S. H. (2005). A practical guide to forecasting financial market volatility. Chi Chester, UK: John Wiley and Sons.
[40] Engle, R. F., Lilien, D., and Robins, R. (1987). Estimating time varying risk premier in the term structure: The Arch-M model. Econometrica 55 (2), 391-407.

[41] Enders, W. (2008). Applied econometric time series. USA: John Wiley and Sons.

[42] Negroponte, D. V. (Ed.). (2013). The end of nostalgia: Mexico confronts the challenges of global competition. Washington, DC: Brookings Institution Press. 